\title{
вмJ Global Health Where are the women? Gender inequalities in COVID-19 research authorship
}

\author{
Ana-Catarina Pinho-Gomes (D) , ${ }^{1}$ Sanne Peters, ${ }^{1,2}$ Kelly Thompson, ${ }^{3}$ \\ Carinna Hockham, ${ }^{3}$ Katherine Ripullone, ${ }^{1}$ Mark Woodward, ${ }^{1,3,4}$ Cheryl Carcel ${ }^{3}$
}

To cite: Pinho-Gomes A-C, Peters S, Thompson K, et al. Where are the women? Gender inequalities in COVID-19 research authorship. BMJ Global Health 2020;5:e002922. doi:10.1136/ bmjgh-2020-002922

Handling editor Seye Abimbola

Received 15 May 2020 Revised 22 May 2020 Accepted 23 May 2020

\section{Check for updates}

(c) Author(s) (or their employer(s)) 2020. Re-use permitted under CC BY-NC. No commercial re-use. See rights and permissions. Published by BMJ.

${ }^{1}$ The George Institute for Global Health, University of Oxford, Oxford, UK

${ }^{2}$ Julius Center for Health Sciences and Primary Care University Medical Center Utrecht, Utrecht University, Utrecht, The Netherlands

${ }^{3}$ The George Institute for Global Health, University of New South Wales, Sydney, New South Wales, Australia

${ }^{4}$ Department of Epidemiology, Johns Hopkins University, Baltimore MD, United States

\section{Correspondence to} Dr Ana-Catarina Pinho-Gomes; ana.pinho-gomes@ georgeinstitute.ox.ac.uk

\section{INTRODUCTION}

Despite some progress over the last decade, gender inequalities persist in academic and research settings. Previous studies have shown that women have a lesser share of authorship positions overall and are less likely than men to be first or last author, the most relevant positions to career progression. ${ }^{1}$ The gap between total authorships for women and men has been stable in recent years, but has grown for senior authorships. ${ }^{2}$

With lockdowns enforced across the globe due to the COVID-19 pandemic, many researchers are now working from home and face competing demands from parenting, homeschooling and other caring duties. These roles are predominantly assumed by women, especially in countries with high gender inequality. Women's representation in research generally, and specifically in the study of COVID-19, may be disproportionately affected by lockdown measures. Underrepresentation of female researchers tends to create under-representation of issues that are relevant to women in research - in our current situation this may create important gaps in our understanding of COVID-19.

Therefore, we investigated whether gender differences existed in authorship of COVID-19 research since the onset of the pandemic. We conducted a systematic search in PubMed, using the MeSH term for 'COVID-19' in Medline, on 1 May 2020. All references were extracted, irrespective of language, study type and date of publication. Differences between women and men were estimated overall and separately for first and last authorship positions. Joint first or last authorships were considered for the analyses of all authors but not for first or last authorship; single authors were included as both first and last authors. Papers where only authors' initials were available or there was a group were excluded.
Summary box

Women account for about a third of all authors who published papers related to COVID-19 since the beginning of the outbreak in January 2020. Women's representation is lower still for first and last authorship positions.

- Gender biases seem to be affecting COVID-19 research similar to other scientific areas, highlighting that women are consistently being under-represented.

- This may have implications for the availability and interrogation of sex-disaggregated data and therefore our understanding of COVID-19.

- These gender biases hint at wider gender inequalities in our global response to the pandemic, which may reduce the chance of dealing with it robustly and speedily.

- Women are under-represented as authors of research papers in many scientific areas, particularly in senior authorship positions.

We estimated the percentage of women as authors overall as well as in first and/or last authorship positions and tested whether these percentages were significantly different from what would be expected under the null hypothesis of equally distributed authorship between genders. Similarly, we estimated, and tested for gender equality the relative percentage of women in the author list of each paper.

In addition, we performed subgroup analyses according to region, time of publication, type of article and impact factor of the journal. The country of origin was defined by the affiliation of the first author and countries were grouped into continents. Time of publication was taken as the date when the record of the paper was created in PubMed. Type of article was split into case report, journal article, editorial, letter, comment, news and other. Impact factor was considered 


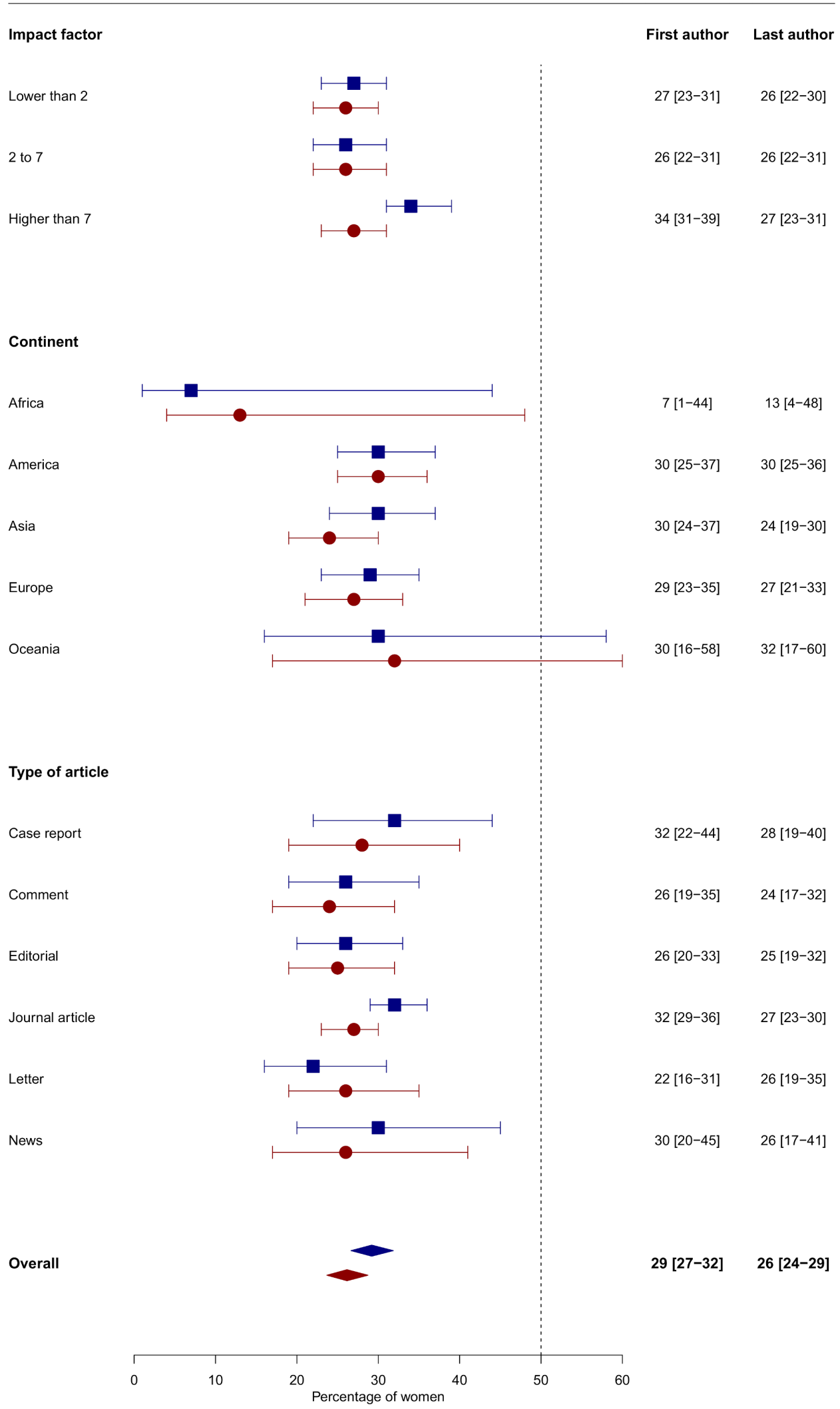

Figure 1 Women in first and last authorship positions of COVID-19-related papers according to journal impact factor, continent and type of article. Values represent percentages of women as first and last authors with respective $95 \%$ Cls.

both as a continuous variable and a categorical variable with three levels: lower than 2, 2-7 and $>7$, reflecting an approximately equal distribution of papers by impact factor. Our analysis has two potential limitations. First, we did not include preprints. However, those preprints have not been peer reviewed, and including them would risk 


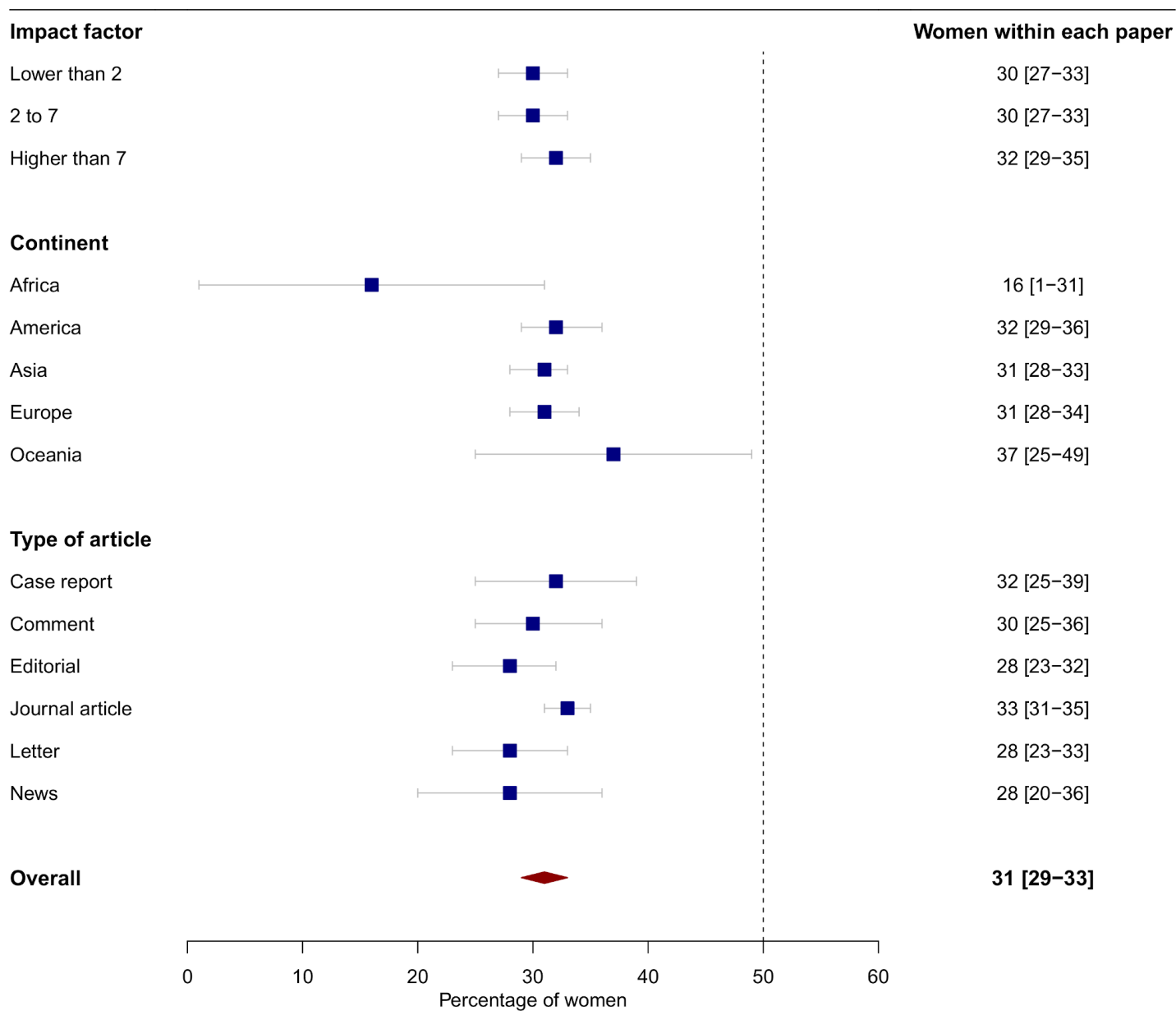

Figure 2 Relative representation of women within the authorship lists of COVID-19-related papers according to journal impact factor, continent and type of article. Values represent percentages of women among all authors for each paper with respective 95\% Cls.

double counting papers. Second, although we employed a widely used and validated software, it is still possible that it may have misclassified the gender of some authors.

\section{FEWER WOMEN AS FIRST AND LAST AUTHORS IN COVID-19 RESEARCH PUBLICATIONS}

We identified 1445 papers related to COVID-19, of which 1370 were included in the overall analysis, with a total of 6722 authors. After applying the aforementioned exclusion criteria, we included 1235 and 1216 papers in the analysis for first or last author, respectively. Overall, women represented $34 \%$ (95\% CI $33 \%$ to $35 \%$, $\mathrm{p}<0.001$ ) of all authors, irrespective of the position. The percentage of women as first and last authors was lower (29\%, $95 \%$ CI $27 \%$ to $32 \%$; and $26 \%, 95 \%$ CI $24 \%$ to $29 \%, \mathrm{p}<0.001$, respectively) (figure 1). If both first and last positions were considered together, the percentage of women was $42 \%$ (95\% CI $39 \%$ to $45 \%, \mathrm{p}<0.001)$. There were no major differences in the percentage of women as first or last author according to region and type of article (figure 1).

Although women's representation was lowest in Africa, the wide CIs precluded drawing definite conclusions. The percentage of women as first author was higher in journals with impact factor above 7 in comparison with those with impact factor below 2, but there were no differences for the last author position between impact factor categories. The mean percentage of female authors within each article was $31 \%$ (95\% CI $29 \%$ to $33 \%$ ), with no evidence of significant differences according to type of paper or journal impact factor (figure 2). However, there were differences between regions, with the lowest percentage observed in Africa and the highest percentage in Oceania. The proportion of women as first and last authors, as well as the proportion of women within each article, has remained broadly consistent since the emergence of COVID-19.

\section{REASONS FOR UNDER-REPRESENTATION OF WOMEN IN COVID-19 AUTHORSHIPS}

The low percentage of female authors was in keeping with similar studies in other areas of research. In an analysis of 20 years of publication in high-impact general medical journals, female first authorships were seen in $34 \%$ of the articles. This study also demonstrated that female first authors in infectious disease publication topics declined by $4 \%$ from 1994 to $2014 .^{3}$ In a 2017 study of 1.5 million research papers, women comprised $40 \%$ of 
first authors and $27 \%$ of last authors. ${ }^{4}$ Our figures are lower than these two studies for first authors $(29 \%)$ and last authors (26\%). This shows that raising awareness on gender inequalities in research in general, and in authorship of papers in particular, has not led to substantial improvements. ${ }^{5}$ It is possible that the current restrictions imposed during the COVID-19 pandemic have contributed further to this decline.

In the case of COVID-19-related research, the reasons for under-representation can be manifold. First, COVID-19 research may be shaped by those in leadership positions, who remain more often men. Second, COVID-19 is a high-profile and dynamic topic where women may either be overtly or covertly denied access to COVID-19 research, because of its anticipated high impact. ${ }^{6}$ Third, women may have less time to commit to research during the pandemic. ${ }^{7}$ Fourth, COVID-19related papers are likely to be affected as much as other papers by gender bias in the peer-review process. ${ }^{8}$ Fifth, a relatively large amount of the early COVID-19 publications are commissioned articles, which are, in general, more likely to be published by men. ${ }^{9}$

There is a pressing need to reduce these gender inequalities because women's participation in research is associated with a higher likelihood of reporting gender and sex-disaggregated data, ${ }^{4}$ which in turn improve our understanding of the clinical and epidemiological dimensions of COVID-19. This is especially true as evidence continues to accrue regarding sex and gender differences in mortality rates and in the long-term economic and societal impacts of COVID-19, making a balanced gender perspective ever more important. ${ }^{1011}$

One possible solution to overcome the persistently low representation of women in authorship of scientific papers in general and COVID-19 papers specifically would be to promote voluntary disclosure of gender as part of the submission process. This would allow editorial teams to monitor gender inequalities in authorship and it would encourage research teams to foster equality in authorship. A further step would be to consider gender quotas, as these have shown to help rectify women's underrepresentation in prominent positions, for instance, in political, economic and academic systems. ${ }^{12}$

\section{CONCLUSION}

Women have been under-represented in COVID-19 research since the beginning of the outbreak. Gender equality and inclusiveness in COVID-19 research are key to succeed in the global fight against the pandemic. The disproportionate contribution of women to COVID-19 research reflects a broader gender bias in science that should be addressed for the benefit of men and women alike.

Twitter Ana-Catarina Pinho-Gomes @ana_cat_pg

Contributors All authors were involved in the design of the study. ACPG conducted the analysis and drafted the manuscript. All authors reviewed and approved the manuscript. CC is the guarantor of the study. The guarantor accepts full responsibility for the work and/or the conduct of the study, had access to the data and controlled the decision to publish.

Funding This study was funded by COVID-19 research grant from the University of New South Wales.

Competing interests MW is a consultant to Amgen and Kirin; no other relationships or activities could appear to have influenced the submitted work.

Patient consent for publication Not required.

Provenance and peer review Not commissioned; externally peer reviewed.

Data availability statement All data relevant to the study are included in the article.

Open access This is an open access article distributed in accordance with the Creative Commons Attribution Non Commercial (CC BY-NC 4.0) license, which permits others to distribute, remix, adapt, build upon this work non-commercially, and license their derivative works on different terms, provided the original work is properly cited, appropriate credit is given, any changes made indicated, and the use is non-commercial. See: http://creativecommons.org/licenses/by-nc/4.0/.

\section{ORCID iD}

Ana-Catarina Pinho-Gomes http://orcid.org/0000-0001-9895-1493

\section{REFERENCES}

1 Bendels MHK, Wanke E, Schöffel N, et al. Gender equality in academic research on epilepsy-a study on scientific authorships. Epilepsia 2017:58:1794-802.

2 Lerchenmüller C, Lerchenmueller MJ, Sorenson O. Longterm analysis of sex differences in prestigious Authorships in cardiovascular research supported by the National Institutes of health. Circulation 2018;137:880-2.

3 Filardo G, da Graca B, Sass DM, et al. Trends and comparison of female first authorship in high impact medical journals: observational study (1994-2014). BMJ 2016;352:i847.

4 Nielsen MW, Andersen JP, Schiebinger L, et al. One and a half million medical papers reveal a link between author gender and attention to gender and sex analysis. Nat Hum Behav 2017;1:791-6.

5 Nature. Nature's under-representation of women. Nature 2018;558:344.

6 Rajan D, Koch K, Rohrer K, et al. Governance of the Covid-19 response: a call for more inclusive and transparent decision-making. BMJ Glob Health 2020;5:e002655.

7 Minello A. The pandemic and the female academic. Nature 2020. doi:10.1038/d41586-020-01135-9. [Epub ahead of print: $17 \mathrm{Apr}$ 2020].

8 Holmes A, Hardy S. Gender bias in peer review - opening up the black box. London, UK: London School of Economics, 2019.

9 Nature. Nature's sexism. Nature 2012;491:495.

10 Douglas M, Katikireddi SV, Taulbut M, et al. Mitigating the wider health effects of covid-19 pandemic response. BMJ 2020;369:m1557.

11 Rexrode KM. The gender gap in first authorship of research papers. BMJ 2016;352:i1130.

12 Turan G, OECD Forum. Why quotas work for gender equality, 2015 Available: http://www.oecd.org/social/quotas-gender-equality.htm [Accessed 10 May 2020]. 